\title{
Correction to: The Past Ubiquity and Environment of the Lost Earth Buildings of Scotland
}

\author{
Simon J. Parkin ${ }^{1}$ - W. Paul Adderley ${ }^{1}$
}

Published online: 30 October 2017

(C) Springer Science+Business Media, LLC 2017

\section{Correction to: Hum Ecol}

https://doi.org/10.1007/s10745-017-9931-4

In the original publication, two pairs of Figures, Fig. 2 and 3, and Fig. 9 and 10 have correct captions but images are reversed. The original article was corrected.

The online version of the original article can be found at https://doi.org/ 10.1007/s10745-017-9931-4

$\triangle$ W. Paul Adderley

w.p.adderley@stir.ac.uk

1 Biological and Environmental Sciences, Faculty of Natural Sciences,

University of Stirling, Stirling, Scotland FK9 4LA, UK 